\title{
Modeling the Fractional Integration in Volatility Between the Greater China Financial Markets
}

\author{
K.Y. Ho ${ }^{\mathrm{a}}$ and Z.Y. Zhang \\ ${ }^{a}$ College of Business and Economics, Australian National University, Australia \\ ${ }^{b}$ School of Accounting, Finance \& Economics, Edith Cowan University, Australia \\ Email: zhaoyong.zhang@ecu.edu.au
}

\begin{abstract}
The dynamics of the interrelationships among the financial markets in the Greater China area including Mainland China, Taiwan, and Hong Kong, is a noteworthy issue of economic research. This is not only because the financial markets in this region have grown rapidly over the past decade, but also because of the arguably asymmetric integration of the emerging Chinese economy with advanced countries in the real side of the economy and tight control over financial market. Since its establishment in the early 1990s, the Mainland Chinese stock market has expanded rapidly in terms of capitalization, turnover, and the new listings. Even though the stock markets in the Greater China region have developed independently and with different institutional features, cross-market linkages can be observed in terms of the increasing number of Mainland companies listed in the Stock Exchange of Hong Kong and closer economic ties in the Greater China region. It is believed common factors that affect all economies drive financial integration, while the emerging markets are more likely to be influenced by local events. Recently there have been a number of studies that assess the financial market integration by employing different GARCH models with time-varying conditional correlations. Despite the growing importance of the Greater China stock markets and their dynamic interactions, there have been only a few studies on this issue with a mixed result. Moreover, most of these studies have not analyzed the volatility dynamics of the Greater China stock markets in a multivariate framework, and there is hardly any extensive discussion of the presence of volatility persistence in these markets. This would create potential model misspecification and may generate biased results.
\end{abstract}

In this study we employ a multivariate framework that incorporates the features of asymmetries, persistence, and time-varying correlations to examine the volatility dynamics of the Greater China stock markets (Shanghai A- and B-shares, Shenzhen A- and B-shares, Taiwan, and Hong Kong). The results indicate that the B-share markets do not exhibit significant asymmetric volatility ("leverage effect"), and return volatility in the A-share market is substantially higher than that in the B-share market before April 1997. Since then, this result is reversed. There is strong evidence of volatility persistence in all the markets, which is robust to changes in model specification. The Greater China stock markets apparently share a common degree of persistence (fractional integration) in volatility. Moreover, the Shenzhen and Shanghai stock exchanges are positively but not perfectly correlated with each other, with the strength of correlation increasing after the late nineties. Their correlations with the Hong Kong and Taiwan markets are much weaker, and they do not display any clear trends. These findings have important implications for hedging and portfolio management and diversification.

Keywords: volatility dynamics; financial market integration; Greater China, asymmetric volatility 
Ho and Zhang, Modeling the Fractional Integration in Volatility Between the Greater China Financial Markets

\section{INTRODUCTION}

The dynamics of the interrelationships among the financial markets in the Greater China area including Mainland China, Taiwan, and Hong Kong, is a noteworthy issue of economic research. This is not only because the financial markets in this region have grown rapidly over the past decade, but also because of the arguably asymmetric integration of the emerging Chinese economy with advanced countries in the real side of the economy and tight control over financial market. Since its establishment in the early 1990s, the Mainland Chinese stock market has expanded rapidly in terms of capitalization, turnover, and the new listings. Even though the stock markets in the Greater China region have developed independently and with different institutional features, cross-market linkages can be observed in terms of the increasing number of Mainland companies listed in the Stock Exchange of Hong Kong and closer economic ties in the Greater China region. It is believed common factors that affect all economies drive financial integration, while the emerging markets are more likely to be influenced by local events. Recently there have been a number of studies that assess the financial market integration by employing different GARCH models with time-varying conditional correlations. Despite the growing importance of the Greater China stock markets and their dynamic interactions, there have been only a few studies on this issue with a mixed result. Moreover, most of these studies have not analyzed the volatility dynamics of the Greater China stock markets in a multivariate framework, and there is hardly any extensive discussion of the presence of volatility persistence in these markets. This would create potential model misspecification and may generate biased results.

This paper proposes a unified approach to the modeling of volatility dynamics of the Greater China area stock markets by adopting a multivariate framework that simultaneously incorporates asymmetries, persistence and dynamic, time-varying correlations. In particular, we adopt two different classes of the generalized autoregressive conditional heteroscedasticity $(\mathrm{GARCH})$ models that nest many popular versions of the GARCH model, to assess the dynamic linkages among the stock markets in the Greater China region and to examine asymmetric volatility and long-memory persistence of shocks in these markets. Strong volatility persistence can have implications for hedging. Our framework ensures the positive-definiteness of the conditional variance-covariance matrix once parameter estimates are obtained. Unlike the bivariate ARCH model of Engle et al. (1984) and the vech-representation of Bollerslev et al. (1988), we do not require excessive restrictions on the parameters to guarantee the positive-definiteness of the variance-covariance matrix. Moreover, our multivariate approach is more parsimonious compared with the Baba-Engle-KraftKroner (BEKK) model of Engle and Kroner (1995) and the factor model of Diebold and Nerlove (1989). Parsimony helps to ensure the tractability of estimating the parameters, especially when many data sets are involved. Also, our approach is more efficient than Engle's (2002) Dynamic Conditional Correlation (DCC) approach, as the parameters for the volatility and correlation equations are concurrently estimated in one step. We believe that it is important to use the multivariate framework to examine the volatility dynamics of the Greater China stock markets, in spite of the potential computational complexities involved. This is partly because many asset returns are subject to similar information or events and their volatilities may be correlated conditional on the given information set. The multivariate framework incorporating the possible asymmetric volatility effects will contribute to our better understanding of the interdependence and integration among the stock markets in the Greater China region. Furthermore, measuring and forecasting financial market volatility is paramount to asset and derivative pricing, asset allocation, and risk management. Understanding how volatility evolves over time in Greater China's stock markets is particularly important for the development of robust derivative markets in this region.

The rest of this paper is organized as follows. Section 2 outlines the econometric methodology employed in this study. The next section then provides brief background information of the stock markets, discusses the data sets employed in this paper, and analyzes the estimation results. Section 4 concludes with some remarks on the implications of our findings.

\section{METHODOLOGY AND THE MODEL}

We first briefly describe the basic features of the multivariate $\operatorname{GARCH}(1,1)$ model with time-varying (dynamic) conditional correlations and then extend the model to incorporate the features of asymmetric volatility and long-memory persistence.

Let $y_{t}=\left(y_{1 t}, y_{2 t}, y_{3 t} \ldots y_{k t}\right)$ be the $k$-variate vector of variables with time-varying variance-covariance matrix $\mathrm{H}_{\mathrm{t}}$, and let $\mu_{i t}\left(\xi_{\mathrm{i}}\right)$ be the arbitrary conditional mean functions which depend on $\xi_{i}$, a column vector of parameters, for $i=1,2, \ldots, \mathrm{k}$. A typical k-variate $\operatorname{GARCH}(1,1)$ model can be specified as follows: 
Ho and Zhang, Modeling the Fractional Integration in Volatility Between the Greater China Financial Markets

$y_{i t}=\mu_{i t}\left(\xi_{i}\right)+\varepsilon_{i t}, \quad i=1,2, \ldots, k$

where $\left(\varepsilon_{1 t}, \varepsilon_{2 t}, \varepsilon_{3 t}, \ldots, \varepsilon_{k t}\right)^{\prime} \mid \Phi_{t-1} \sim\left(O, H_{t}\right) . \Phi_{\mathrm{t}}$ is the $\sigma$-algebra generated by all the available information up to time $t$. The random disturbance terms $\varepsilon_{i t}$ and the conditional variance equations $h_{i i t}$ are modeled as follows:

$\varepsilon_{i t}=\sqrt{h_{i i t}} e_{i t}, \quad$ where $e_{i t} \sim N(0,1)$

$h_{i i t}=\eta_{i}+\alpha_{i} \varepsilon_{i t-1}^{2}+\beta_{i} h_{i i t-1}, \quad i=1, \ldots, k$

where (3) is the popular Bollerslev's (1986) GARCH(1,1) model.

Denoting the $i j$-th element $(\mathrm{i}, \mathrm{j}=1,2, \ldots, \mathrm{k})$ in $H_{t}$ by $h_{i j t}$, the conditional correlation coefficients are given by $\rho_{i j t}=\frac{h_{i j t}}{\sqrt{h_{i i t} h_{j j t}}}$. Tse and Tsui (2002) assume that the time-varying conditional correlation matrix $\Gamma_{t}=\left\{\rho_{i j t}\right\}$ is generated by the following recursion

$\boldsymbol{\Gamma}_{t}=\left(1-\pi_{1}-\pi_{2}\right) \boldsymbol{\Gamma}+\pi_{1} \boldsymbol{\Gamma}_{t-1}+\pi_{2} \Psi_{t-1}$

where $\Gamma=\left\{\rho_{i j}\right\}$ is a time-invariant ( $\mathrm{k} \mathrm{x} \mathrm{k)}$ positive-definite correlation matrix, $\pi_{1}$ and $\pi_{2}$ are assumed to be nonnegative and sum up to less than 1 , and $\Psi_{\mathrm{t}}$ is a function of the standardized residuals $e_{i t}$. Thus, $\Gamma_{t}$ is a weighted average of $\Gamma, \Gamma_{t-1}$, and $\Psi_{t-1}$.

Assuming conditional normality of the variables, the log-likelihood function of the model can be specified as

$l_{t}(\theta)=-\frac{1}{2} \log \left|H_{t}\right|-\frac{1}{2}\left(\varepsilon_{1 t}, \varepsilon_{2 t}, \varepsilon_{3 t}, \ldots, \varepsilon_{k t}\right) H_{t}^{-1}\left(\varepsilon_{1 t}, \varepsilon_{2 t}, \varepsilon_{3 t}, \ldots, \varepsilon_{k t}\right)^{\prime}$

where $\varepsilon_{\text {it }}$ are the random disturbance terms obtained from equation (1), and $H_{t}$ is the conditional variancecovariance matrix.

Equations (1)-(5) summarize the gist of the varying-correlations GARCH (VC-GARCH) model of Tse and Tsui (2002). As noted by Tse and Tsui (2002), Bollerslev's (1990) constant-correlations GARCH (CCGARCH) model is nested within the VC-GARCH model under the restrictions $\pi_{1}=\pi_{2}=0$. Thus, the likelihood ratio test can be readily applied to compare the performance of these two models.

In order to incorporate the feature of asymmetric volatility in the VC-GARCH model, we choose the following two well-established structures, namely the quadratic $\operatorname{GARCH}(1,1)$ (QGARCH(1,1)) model proposed by Sentana (1995), which is closely associated with Engle's (1990) asymmetric GARCH $(1,1)$ (AGARCH(1,1)) model; and the asymmetric power $\operatorname{ARCH}(1,1)(\operatorname{APARCH}(1,1))$ model of Ding et al. (1993). The QGARCH(1,1) model is specified as follows:

$$
h_{t}=\eta-\gamma \varepsilon_{t-1}+\alpha \varepsilon_{t-1}^{2}+\beta h_{t-1}
$$

where $\gamma$ is the asymmetric coefficient. When $\gamma=0$, equation (6) becomes the $\operatorname{GARCH}(1,1)$ model, and when $\gamma=\beta=0$, it becomes the prototype $\operatorname{ARCH}(1)$ model. The asymmetric power $\operatorname{ARCH}(1,1)$ model can be specified as follows:

$$
h_{t}^{\delta / 2}=\eta+\alpha\left(\left|\varepsilon_{t-1}\right|-\gamma \varepsilon_{t-1}\right)^{\delta}+\beta h_{t-1}^{\delta / 2}
$$


Ho and Zhang, Modeling the Fractional Integration in Volatility Between the Greater China Financial Markets

where $\gamma$ is the asymmetric coefficient.

To model the long-memory dynamics in volatility, we derive the fractionally integrated asymmetric GARCH (FIAGARCH) model by generalizing the conditional variance equations following the BBM procedure (Baillie et al., 1996), expressed as follows,

$$
h_{t}=\frac{\eta^{*}}{1-\beta}+\lambda(L)\left(\varepsilon_{t}-\gamma^{*}\right)^{2}
$$

where $\lambda(L)=\sum_{a=1}^{\infty} \lambda_{a} L^{a}=1-(1-\beta L)^{-1}(1-\phi L)(1-L)^{d}$. And the Fractionally Integrated Asymmetric Power ARCH (FIAPARCH(p,d,q)) model modifies the FIGARCH process to allow for asymmetries, which can be specified as,

$$
h_{t}^{\delta / 2}=\frac{\eta}{1-\beta(1)}+\left[1-(1-\beta(L))^{-1} \phi(L)(1-L)^{d}\right] g\left(\varepsilon_{t}\right)^{\delta}
$$

In particular, the FIAPARCH $(1, \mathrm{~d}, 1)$ model is specified as:

$$
h_{t}^{\delta / 2}=\frac{\eta}{1-\beta}+\lambda(L)\left(\left|\varepsilon_{t}\right|-\gamma \varepsilon_{t}\right)^{\delta}
$$

Similar to the FIAGARCH(1,d,1) model, the FIAPARCH $(1, \mathrm{~d}, 1)$ model allows past shocks to have asymmetric effects on the conditional volatility. When $\gamma>0$, negative shocks give rise to higher volatility than positive ones. The reverse applies if $\gamma<0$.

The parameters of the different multivariate fractionally integrated GARCH-type models can be estimated using Bollerslev and Wooldridge's (1992) quasi-maximum likelihood estimation (QMLE) approach. To facilitate convergence in the estimation, we have to make appropriate assumptions for the start-up conditions, including the computation of $\lambda(L)$, the number of lags, and the initial values. As regards the choice of initial values, we set the presample observations $\varepsilon_{t}^{2}$ to the unconditional sample variance for the $\operatorname{FIGARCH}(1, \mathrm{~d}, 1)$ model. However, this assumption may be inappropriate for the other models, as the infinite $\mathrm{ARCH}$ representation affects $g\left(\varepsilon_{t}\right)$. Therefore, for the multivariate $\operatorname{FIAGARCH}(1, \mathrm{~d}, 1)$ model, we equate the presample observations of $g\left(\varepsilon_{t}\right)=\left(\varepsilon_{t}-\gamma^{*}\right)^{2}$ to the sample mean of $\left(\hat{\varepsilon}_{t}-\hat{\gamma}^{*}\right)^{2}$, where $\hat{\gamma}^{*}$ is the estimate of $\gamma *$ based on the univariate $\operatorname{FIAGARCH}(1, \mathrm{~d}, 1)$ model. As for the multivariate FIAPARCH(1,d,1) model, the presample observations of $g\left(\varepsilon_{t}\right)^{\delta}=\left(\left|\varepsilon_{t}\right|-\gamma \varepsilon_{t}\right)^{\delta}$ are equated to the sample mean of $\left(\left|\hat{\varepsilon}_{t}\right|-\hat{\gamma} \hat{\varepsilon}_{t}\right)^{\hat{\delta}}$, where $\hat{\gamma}$ and $\hat{\delta}$ are the estimates of $\gamma$ and $\delta$ based on the univariate FIAPARCH $(1, \mathrm{~d}, 1)$ model.

\section{EMPIRICAL ANALYSIS}

\subsection{Data Description}

The following data sets are used to examine the volatility dynamics of the Greater China markets: the Shanghai Composite Index (SHSCOMP), the Shenzhen Composite Index (SHZCOMP), the Taiwan Weighted Index (TAIWGHT), the Hang Seng Index (HNGKNGI), the Shanghai A-share and B-share Indices (SHSASHR, SHZBSHR), and the Shenzhen A-share and B-share Indices (SHZASHR, SHZBSHR). All four markets commenced trading on different dates: the oldest market is the Hong Kong Stock Exchange Ltd, which was formed in 1947, whereas the youngest market is the Shenzhen market, which started on April 3, 1991. The Shanghai market started trading slightly earlier than Shenzhen market on December 19, 1990. During the period from December 19, 1990 to May 20, 1992, the government imposed a daily price limit on the Shanghai market, which restricted changes to the share price within a $5 \%$ band. This limit was finally lifted on May 21, 1992. As such, our analysis of the Greater China stock markets will begin from May 22, 1992. Specifically, for the SHSCOMP, SHZCOMP, TAIWGHT, and HNGKNGI indices, the data sets 
Ho and Zhang, Modeling the Fractional Integration in Volatility Between the Greater China Financial Markets

comprise 3636 daily price observations spanning from May 22, 1992 to April 28, 2006. As for the A-share and B-share indices, instead of May 22, 1992, the start date of our analysis is October 5, 1992, because this is the very first day of availability for the Shenzhen A-share and Bshare indices. All data sets are obtained from DataStream International.

Table 1 displays the key descriptive statistics of the daily returns of the data sets used in this paper. The daily returns are computed on a continuously compounding basis by taking the difference of the logarithms of the daily stock market price indices. As shown in Table 1, excess kurtosis is noted for all markets, and the Shanghai Composite index has the highest kurtosis coefficient. Also, as measured by the standard deviation of the data sets, the Shanghai and the Shenzhen Composite Indices are relatively more volatile. This observation is apparently consistent with papers that highlight the fact that emerging stock markets are generally more volatile than their developed counterparts (see Bekaert et al., 2005; Aggarwal et al., 1999; Gao, 2002). The McLeod-Li, ARCH LM and QARCH LM tests suggest that conditional heteroskedasticity may be present in all the data series. This finding is further corroborated by the BDS test. Under the null hypothesis of independence, the BDS test statistic has an asymptotic standard normal distribution.

\subsection{Empirical Results}

We have estimated three different combinations of the stock markets in the Greater China region, and report in Table 2 the estimation results of the VC-GARCH, VC-QGARCH and VC-APARCH for the group including HKNGI, TWGHI, CHSASHR and CHZASHR. Tables 3 and 4 reports the estimation results of FIGARCH, FIAGARCH and FIAPARCH, and the asymmetric parameters. The results for other two groups are available upon request.

\begin{tabular}{|c|c|c|c|c|c|c|c|c|c|c|c|c|c|c|c|}
\hline Variable & $\eta$ & $\beta$ & $\alpha$ & $\gamma$ & $\delta$ & $\mu_{0}$ & $\mu_{1}$ & $\Gamma$ & & $\pi_{1}$ & $\pi_{2}$ & $\mathrm{LL}(\mathrm{VC})$ & \multicolumn{2}{|c|}{ Corr (CC) } & $\mathrm{LL}(\mathrm{CC})$ \\
\hline \multicolumn{16}{|c|}{ Panel A: VC-GARCH } \\
\hline \multirow[t]{2}{*}{ TAIWGHT } & \multirow[t]{2}{*}{$\begin{array}{l}0.0796 \\
(0.0271)\end{array}$} & \multirow[t]{2}{*}{$\begin{array}{l}0.9043 \\
(0.0185)\end{array}$} & \multirow[t]{2}{*}{$\begin{array}{l}0.0694 \\
(0.0125)\end{array}$} & & - & \multirow[t]{2}{*}{\begin{tabular}{|l|}
0.0536 \\
$(0.0284)$
\end{tabular}} & \multirow[t]{2}{*}{$\begin{array}{l}0.0288 \\
(0.0174)\end{array}$} & $\rho_{T H}=$ & $\begin{array}{l}0.3250 \\
(0.0520)\end{array}$ & \multirow[t]{8}{*}{$\begin{array}{l}0.9513 \\
(0.0077)\end{array}$} & \multirow[t]{8}{*}{$\begin{array}{l}0.0321 \\
(0.0043)\end{array}$} & \multirow[t]{8}{*}{-9506.8053} & $\rho_{T H}=$ & $\begin{array}{l}0.2447 \\
(0.0185)\end{array}$ & \multirow[t]{8}{*}{-10529.84896} \\
\hline & & & & & & & & \multirow[t]{2}{*}{$\rho_{T S}=$} & 0.0696 & & & & \multirow[t]{2}{*}{$\rho_{\text {TS }}=$} & 0.0220 & \\
\hline \multirow[t]{2}{*}{ HNGKNGI } & 0.0298 & 0.9196 & 0.0730 & . & . & 0.0666 & 0.0376 & & $(0.0502)$ & & & & & $(0.0190)$ & \\
\hline & $(0.0110)$ & $(0.0126)$ & $(0.0121)$ & & & $(0.0240)$ & $(0.0179)$ & $\rho_{\mathrm{TZ}}=$ & 0.0686 & & & & $\rho_{\mathrm{TZ}}=$ & 0.0338 & \\
\hline \multirow[t]{2}{*}{ CHSASHR } & \multirow{2}{*}{$\begin{array}{l}0.0120 \\
(0.0081)\end{array}$} & \multirow{2}{*}{$\begin{array}{l}0.9386 \\
(0.0120)\end{array}$} & \multirow{2}{*}{$\begin{array}{l}0.0721 \\
(0.0142)\end{array}$} & \multirow[t]{2}{*}{-} & \multirow[t]{2}{*}{-} & \multirow{2}{*}{\begin{tabular}{|l|}
-0.0128 \\
$(0.0063)$
\end{tabular}} & \multirow{2}{*}{$\begin{array}{l}0.0198 \\
(0.0128)\end{array}$} & $\rho_{\mathrm{HS}}=$ & 0.0159 & & & & $\rho_{\mathrm{HS}}=$ & 0.0452 & \\
\hline & & & & & & & & \multirow[t]{2}{*}{$\rho_{\mathrm{HZ}}=$} & $\frac{(0.0020)}{0.0460}$ & & & & \multirow[t]{2}{*}{$\rho_{\mathrm{HZ}}=$} & 0.0557 & \\
\hline \multirow[t]{2}{*}{ CHZASHR } & 0.0124 & 0.9388 & 0.0710 & . & . & -0.0288 & 0.0309 & & $(0.0326)$ & & & & & $(0.0171)$ & \\
\hline & $(0.0091)$ & $(0.0136)$ & $(0.0154)$ & & & $(0.0092)$ & $(0.0129)$ & $\rho_{\mathrm{sz}}=$ & $\begin{array}{l}0.9856 \\
(0.0042)\end{array}$ & & & & $\rho_{S Z}=$ & $\begin{array}{l}0.8851 \\
(0.0108)\end{array}$ & \\
\hline \multicolumn{16}{|c|}{ Panel B: VC-QGARCH } \\
\hline \multirow[t]{2}{*}{ TAIWGHT } & \multirow[t]{2}{*}{$\begin{array}{l}0.1355 \\
(0.0491)\end{array}$} & $\begin{array}{l}0.8733 \\
(0.0290)\end{array}$ & $\begin{array}{l}0.0800 \\
(0.0146)\end{array}$ & $\begin{array}{l}0.1518 \\
(0.0430)\end{array}$ & - & \begin{tabular}{|l|}
0.0130 \\
$(0.0223)$
\end{tabular} & $\begin{array}{l}0.0323 \\
(0.0176)\end{array}$ & $\rho_{\text {TH }}=$ & $\begin{array}{l}0.3208 \\
(0.0507)\end{array}$ & $\begin{array}{l}0.9502 \\
(0.0077)\end{array}$ & $\begin{array}{l}0.0330 \\
(0.0043)\end{array}$ & -9446.12208 & $\rho_{\text {TH }}=$ & $\begin{array}{l}0.2413 \\
(0.0182)\end{array}$ & -10476.36016 \\
\hline & & & & & & & & $\rho_{\text {TS }}=$ & 0.0631 & & & & $\rho_{\mathrm{TS}}=$ & 0.0191 & \\
\hline HNGKNGI & 0.0453 & 0.9122 & 0.0734 & 0.0865 & - & 0.0321 & 0.0457 & & $(0.0628)$ & & & & & $(0.0169)$ & \\
\hline & $(0.0147)$ & $(0.0128)$ & $(0.0109)$ & $(0.0267)$ & & $(0.0231)$ & $(0.0187)$ & $\rho_{\mathrm{TZ}}=$ & $\begin{array}{l}0.0618 \\
(0.0630)\end{array}$ & & & & $\rho_{\mathrm{TZ}}=$ & $\begin{array}{l}0.0328 \\
(0.0176)\end{array}$ & \\
\hline CHSASHR & 0.0134 & 0.9392 & 0.0706 & 0.0317 & - & -0.0172 & 0.0236 & $\rho_{\mathrm{HS}}=$ & 0.0115 & & & & $\rho_{\mathrm{HS}}=$ & 0.0416 & \\
\hline & $(0.0076)$ & $(0.0115)$ & $(0.0134)$ & $(0.0158)$ & & $(0.0127)$ & $(0.0155)$ & $\rho \mathrm{PHz}=$ & $\frac{(0.1039)}{0.0405}$ & & & & $\rho \mathrm{Hz}=$ & $\frac{(0.0182)}{0.0529}$ & \\
\hline CHZASHR & 0.0141 & 0.9396 & 0.0692 & 0.0390 & . & -0.0351 & 0.0334 & & $(0.1006)$ & & & & & $(0.0184)$ & \\
\hline & $(0.0083)$ & $(0.0124)$ & $(0.0139)$ & $(0.0156)$ & & $(0.0151)$ & $(0.0152)$ & $\rho_{\mathrm{sz}}=$ & $\begin{array}{l}0.9859 \\
(0.0041)\end{array}$ & & & & $\rho_{\mathrm{sz}}=$ & $\begin{array}{l}0.8840 \\
(0.0108)\end{array}$ & \\
\hline
\end{tabular}


Ho and Zhang, Modeling the Fractional Integration in Volatility Between the Greater China Financial Markets

\begin{tabular}{|c|c|c|c|c|c|c|c|c|c|c|c|c|c|}
\hline \multicolumn{14}{|c|}{\begin{tabular}{|l|l} 
Panel C: VC-APARCH \\
\end{tabular}} \\
\hline \multirow[t]{2}{*}{ TAIWGHT } & \multirow[t]{2}{*}{$\begin{array}{l}0.1006 \\
(0.0356)\end{array}$} & \multirow[t]{2}{*}{$\begin{array}{l}0.8874 \\
(0.0239)\end{array}$} & \multirow[t]{2}{*}{$\begin{array}{l}0.0746 \\
(0.0151)\end{array}$} & \multirow[t]{2}{*}{$\begin{array}{l}0.3073 \\
(0.0766)\end{array}$} & \multirow[t]{2}{*}{$\begin{array}{l}1.9472 \\
(0.3217)\end{array}$} & \multirow[t]{2}{*}{$\begin{array}{l}0.0130 \\
(0.0254)\end{array}$} & \multirow[t]{2}{*}{$\begin{array}{l}0.0352 \\
(0.0176)\end{array}$} & & $\begin{array}{l}0.3240 \\
(0.0501)\end{array}$ & \multirow[t]{8}{*}{$\begin{array}{l}0.9499 \\
(0.0078)\end{array}$} & \multirow[t]{8}{*}{$\begin{array}{l}0.0330 \\
(0.0043)\end{array}$} & \multirow[t]{8}{*}{$\begin{array}{l}-9416.844 \\
\end{array}$} & - \\
\hline & & & & & & & & \multirow{2}{*}{\multicolumn{2}{|c|}{\begin{tabular}{rl|}
$\rho_{\text {TS }}=$ & 0.0626 \\
& $(0.0498)$ \\
\end{tabular}}} & & & & 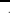 \\
\hline \multirow[t]{2}{*}{ HNGKNGI } & 0.0307 & 0.9246 & \begin{tabular}{|l|}
0.0729 \\
\end{tabular} & 0.3687 & 1.4283 & 0.0243 & 0.0465 & & & & & & \\
\hline & $(0.0099)$ & $(0.0104)$ & $(0.0102)$ & $(0.0813)$ & $(0.1693)$ & $(0.0244)$ & $(0.0181)$ & $\rho_{\mathrm{TZ}}=$ & $\begin{array}{l}0.0610 \\
(0.0506)\end{array}$ & & & & 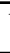 \\
\hline \multirow[t]{2}{*}{ CHSASHR } & \multirow[t]{2}{*}{\begin{tabular}{|l|}
0.0085 \\
$(0.0062)$
\end{tabular}} & \multirow[t]{2}{*}{\begin{tabular}{|l|}
0.9444 \\
$(0.0096)$
\end{tabular}} & \multirow[t]{2}{*}{\begin{tabular}{|l|}
0.0751 \\
$(0.0125)$
\end{tabular}} & \multirow[t]{2}{*}{$\begin{array}{l}0.1294 \\
(0.0569)\end{array}$} & \multirow[t]{2}{*}{\begin{tabular}{|l|}
1.5597 \\
$(0.1440)$
\end{tabular}} & \multirow[t]{2}{*}{$\begin{array}{l}-0.0155 \\
(0.0129)\end{array}$} & \multirow[t]{2}{*}{\begin{tabular}{|l|}
0.0229 \\
$(0.0165)$
\end{tabular}} & & $\begin{array}{l}0.0094 \\
(0.0341) \\
\end{array}$ & & & & 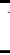 \\
\hline & & & & & & & & $\rho_{\mathrm{HZ}}=$ & 0.0363 & & & & \\
\hline \multirow[t]{2}{*}{ CHZASHR } & 0.0087 & 0.9436 & 0.0749 & 0.1426 & 1.5706 & -0.0335 & 0.0322 & & $(0.0357)$ & & & & \\
\hline & $(0.0069)$ & $(0.0108)$ & $(0.0138)$ & $(0.0537)$ & $(0.1574)$ & $(0.0156)$ & $(0.0170)$ & $\rho_{\mathrm{sz}}=$ & $\begin{array}{l}0.9850 \\
(0.0041)\end{array}$ & & & & 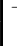 \\
\hline
\end{tabular}

Table 3: Estimation Results of Stock Indices Using HKNGI, TWGHI, CHSASHR and CHZASHR (Oct 51992 - Apr 28 2006)

\begin{tabular}{|c|c|c|c|c|c|c|c|c|c|c|c|c|c|c|}
\hline \multirow{2}{*}{\multicolumn{14}{|c|}{\begin{tabular}{l|ll|} 
Variable & $\eta$ & 0 \\
Panel A: VC-FIAGARCH
\end{tabular}}} & \\
\hline & & & & & & & & & & & & & & \\
\hline \multirow[t]{2}{*}{ TAIWGHT } & \multirow[t]{2}{*}{$\begin{array}{l}-0.2241 \\
(0.1899)\end{array}$} & \multirow[t]{2}{*}{$\begin{array}{l}-0.1128 \\
(0.1004)\end{array}$} & \multirow[t]{2}{*}{$\begin{array}{l}0.8181 \\
(0.1334)\end{array}$} & \multirow[t]{2}{*}{ - } & \multirow[t]{2}{*}{$\begin{array}{l}0.0858 \\
(0.1213)\end{array}$} & \multirow[t]{2}{*}{$\begin{array}{l}0.2903 \\
(0.0376)\end{array}$} & \multirow[t]{2}{*}{$\begin{array}{l}0.0177 \\
(0.0262)\end{array}$} & \multirow[t]{2}{*}{$\begin{array}{l}0.0331 \\
(0.0170)\end{array}$} & $\rho_{T H}=$ & $\begin{array}{l}0.3514 \\
(0.0533) \\
\end{array}$ & \multirow[t]{8}{*}{$\begin{array}{l}0.9560 \\
(0.0058)\end{array}$} & \multirow[t]{8}{*}{$\begin{array}{l}0.0313 \\
(0.0038)\end{array}$} & $\rho_{\mathrm{TH}}=$ & $\begin{array}{l}0.2401 \\
(0.0185) \\
\end{array}$ \\
\hline & & & & & & & & & \multirow{2}{*}{$\rho_{\text {TS }}=$} & 0.0805 & & & \multirow[t]{2}{*}{$\rho$ TS $=$} & 0.0140 \\
\hline \multirow[t]{2}{*}{ HNGKNGI } & -0.0343 & 0.1536 & 0.5199 & - & 0.4053 & 0.3394 & 0.0407 & 0.0469 & & $(0.0571)$ & & & & $(0.0205)$ \\
\hline & $(0.0879)$ & $(0.1678)$ & $(0.1358)$ & & $(0.2153)$ & $(0.0641)$ & $(0.0242)$ & $(0.0184)$ & $\rho_{\mathrm{TZ}}=$ & $\begin{array}{l}0.0724 \\
(0.0579) \\
\end{array}$ & & & $\overline{\rho_{\mathrm{TZ}}}=$ & $\begin{array}{l}0.0300 \\
(0.0208) \\
\end{array}$ \\
\hline \multirow[t]{2}{*}{ CHSASHR } & \multirow[t]{2}{*}{$\begin{array}{l}0.1169 \\
(0.0557)\end{array}$} & \multirow[t]{2}{*}{$\begin{array}{l}0.1597 \\
(0.1007)\end{array}$} & \multirow[t]{2}{*}{$\begin{array}{l}0.1871 \\
(0.1059)\end{array}$} & \multirow[t]{2}{*}{ - } & \multirow[t]{2}{*}{$\begin{array}{l}0.3766 \\
(0.0959)\end{array}$} & \multirow[t]{2}{*}{$\begin{array}{l}0.3695 \\
(0.0412)\end{array}$} & \multirow[t]{2}{*}{$\begin{array}{l}-0.0228 \\
(0.0165)\end{array}$} & \multirow[t]{2}{*}{$\begin{array}{l}0.0309 \\
(0.0179)\end{array}$} & & $\begin{array}{l}0.0278 \\
(0.0488) \\
\end{array}$ & & & $\rho_{\mathrm{HS}}=$ & $\begin{array}{l}0.0439 \\
(0.0171) \\
\end{array}$ \\
\hline & & & & & & & & & $\rho_{\mathrm{HZ}}=$ & 0.0583 & & & $\rho_{\mathrm{HZ}}=$ & 0.0547 \\
\hline \multirow{2}{*}{ CHZASHR } & \multirow{2}{*}{$\begin{array}{l}0.0809 \\
(0.0631)\end{array}$} & \multirow{2}{*}{$\begin{array}{l}0.1071 \\
(0.1050)\end{array}$} & \multirow{2}{*}{$\begin{array}{l}0.2719 \\
(0.0941)\end{array}$} & - & 0.3288 & 0.3698 & -0.0386 & 0.0428 & & $(0.0477)$ & & & & $(0.0173)$ \\
\hline & & & & & $(0.1036)$ & $(0.0377)$ & $(0.0183)$ & $(0.0173)$ & $\rho_{\mathrm{sz}}=$ & $\begin{array}{l}0.9745 \\
(0.0054) \\
\end{array}$ & & & $\rho_{\mathrm{sz}}=$ & $\begin{array}{l}0.8486 \\
(0.0096) \\
\end{array}$ \\
\hline Panel B: VC & FIAPARCH & & & & & & & & & & & & & \\
\hline TAIWGHT & $\begin{array}{l}0.3917 \\
(0.1465)\end{array}$ & $\begin{array}{l}-0.1239 \\
(0.1198)\end{array}$ & $\begin{array}{l}0.2713 \\
(0.0685)\end{array}$ & \begin{tabular}{|l|}
1.8765 \\
$(0.2451)$
\end{tabular} & $\begin{array}{l}0.0982 \\
(0.1451)\end{array}$ & $\begin{array}{l}0.2731 \\
(0.0468)\end{array}$ & $\begin{array}{l}0.0095 \\
(0.0236)\end{array}$ & $\begin{array}{l}0.0367 \\
(0.0179)\end{array}$ & 穴H $=$ & $\begin{array}{l}0.3434 \\
(0.0510)\end{array}$ & $\begin{array}{l}0.9538 \\
(0.0069)\end{array}$ & $\begin{array}{l}0.0323 \\
(0.0039)\end{array}$ & $\rho_{\text {TTH }}=$ & $\begin{array}{l}0.2384 \\
(0.0184)\end{array}$ \\
\hline & & & & & & & & & $\rho_{\text {TS }}=$ & 0.0770 & & & $\rho_{\mathrm{TS}}=$ & 0.0149 \\
\hline HNGKNGI & 0.1443 & 0.2261 & 0.3150 & 1.6499 & 0.5361 & 0.3665 & 0.0209 & 0.0522 & & $(0.0530)$ & & & & $(0.0173)$ \\
\hline & (0.0719) & $(0.1066)$ & $(0.0901)$ & $(0.1556)$ & $(0.1933)$ & $(0.1005)$ & $(0.0243)$ & $(0.0178)$ & $\rho_{\mathrm{T} Z}=$ & $\begin{array}{l}0.0689 \\
(0.0535) \\
\end{array}$ & & & $\rho_{\mathrm{TZ}}=$ & $\begin{array}{l}0.0305 \\
(0.0177)\end{array}$ \\
\hline CHSASHR & $\begin{array}{l}0.1132 \\
(0.0676)\end{array}$ & $\begin{array}{l}0.1456 \\
(0.0962)\end{array}$ & $\begin{array}{l}0.0644 \\
(0.0482)\end{array}$ & \begin{tabular}{|l|}
2.0601 \\
$(0.1819)$
\end{tabular} & $\begin{array}{l}0.3706 \\
(0.0932)\end{array}$ & $\begin{array}{l}0.4002 \\
(0.0450)\end{array}$ & $\begin{array}{l}-0.0742 \\
(0.0600)\end{array}$ & $\begin{array}{l}0.0326 \\
(0.0209)\end{array}$ & $\rho \mathrm{HS}=$ & $\begin{array}{l}0.0250 \\
(0.0479)\end{array}$ & & & PHS $=$ & $\begin{array}{l}0.0453 \\
0.0175\end{array}$ \\
\hline & & & & & & & & & $\mathrm{PHz}=$ & 0.0528 & & & $\rho \mathrm{PHz}=$ & 0.0552 \\
\hline CHZASHR & 0.0993 & 0.0877 & 0.0866 & 2.0513 & 0.3236 & 0.4057 & -0.0914 & 0.0386 & & $(0.0479)$ & & & & $(0.0177)$ \\
\hline & $(0.0843)$ & $(0.1043)$ & $(0.0422)$ & $(0.1922)$ & $(0.1058)$ & $(0.0414)$ & $(0.0591)$ & $(0.0209)$ & $\rho_{\mathrm{sz}}=$ & $\begin{array}{l}0.9758 \\
(0.0056)\end{array}$ & & & $\rho_{\mathrm{sz}}=$ & $\begin{array}{l}0.8593 \\
(0.0118) \\
\end{array}$ \\
\hline
\end{tabular}

Note: Corr(CC) are the coefficients of the constant conditional correlation model. The Bollerslev-Wooldridge (1992) standard errors are reported in parentheses.

As it can be seen from Tables 2-4, there is significant evidence that corroborates the existence of asymmetries in the volatility of the Taiwan and Hong Kong stock markets. Both markets exhibit the leverage effect, whereby negative shocks have a greater impact on future volatility levels compared with positive shocks of the same magnitude. Apparently, this finding is robust to changes in model specification and time periods. The estimated values of the asymmetry parameter $\gamma$ for the Taiwan Weighted Index are 0.2519 (0.2713) and 0.0984 (0.8181) for the VC-APARCH (VC-FIAPARCH) and the VC-QGARCH (VCFIAGARCH) models, respectively. The results for the mainland Chinese markets show a similar pattern of return volatility, and both markets display significant leverage effect for the VC-AGARCH, VC-APARCH, VC-FIAPARCH and VC-FIAPARCH models, which is reasonably consistent across different time periods. It is interesting to note that the return volatility of the A-share markets exhibit some evidence of significant asymmetries, but not in the B-share markets. For instance, the asymmetry parameter of the Shenzhen A-share market is significant at approximately $5 \%$ for the VC-FIAGARCH, VC-FIAPARCH, VC-APARCH, and VC-QGARCH models. In the case of the Shanghai A-share market, the parameter $\gamma$ is significant for the VC-FIAGARCH, VC-APARCH and VC-QGARCH models. In contrast, the B-share markets do not display statistically significant leverage effects. The major reasons for the volatility asymmetry of the greater China stock markets may be due to the financial leverage effect; the volatility feedback effects; and the presence of investors with heterogeneous expectations in the stock market. It is noted that there is lack of institutional investor trading in the A-share markets, and the trading values of the Shanghai and Shenzhen stock markets are contributed virtually by the individual investors.

As can be seen from Table 3, the estimated values of the fractional differencing parameter $\mathrm{d}$ for all the

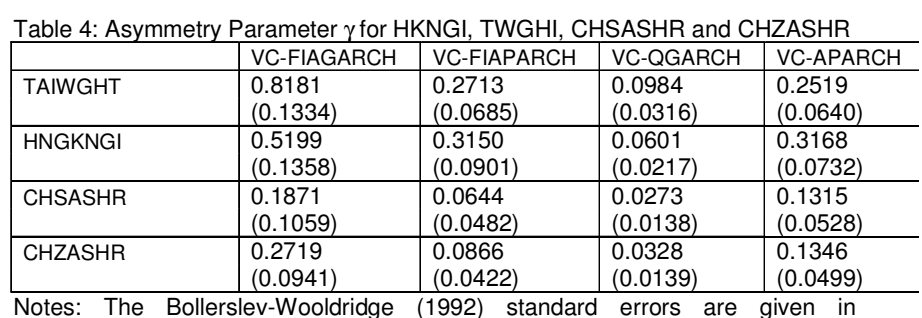
parentheses. 
Ho and Zhang, Modeling the Fractional Integration in Volatility Between the Greater China Financial Markets

markets are significantly different from zero and one. This may suggest that ignoring the feature of asymmetry could overestimate the degree of long range persistence in volatility. The results indicate that there could be a common degree of fractional integration/long memory among some of the markets.

\section{CONCLUDING REMARKS}

We have examined the volatility dynamics of the stock markets of the greater China region using daily returns data from 1992 to 2006, and found the existence of volatility persistence and asymmetries. In particular, the results show that only the B-share markets do not exhibit statistically significant asymmetries, and this result is consistent across different model specifications. Also, conditional correlations among the markets are significantly time-varying. There is some evidence that correlations between some markets are strengthening over time. Judging from the unconditional standard deviation of the returns of the various indices, it appears that the A-share market is more volatile than the B-share market, and that the mainland Chinese markets exhibit greater fluctuations than their counterparts in Hong Kong and Taiwan. However, this claim is misleading when we analyze the conditional volatility of all the markets, since the B-share markets are apparently more volatile than the A-share markets after 1997. Furthermore, there are some periods when the mainland Chinese markets have significantly lower volatility relative to the Hong Kong and Taiwanese markets. This finding suggests that it is not necessarily true that the emerging markets are always more volatile than the developed markets. Equally important, the greater China markets apparently share a common degree of volatility persistence (fractional integration). These findings have various implications for asset allocation and portfolio management.

\section{REFERENCES}

Aggarwal, R., C. Inclan, and R. Leal (1999), 'Volatility in Emerging Stock Markets,' Journal of Financial and Quantitative Analysis, 34, 33-55.

Baillie, R., T. Bollerslev, and H. Mikkelsen (1996), 'Fractionally Integrated Generalized Autoregressive Conditional Heteroskedasticity', Journal of Econometrics, 74, 3-30.

Bekaert, G., C. Harvey, and A. Ng (2005), 'Market integration and contagion', Journal of Business, 78, 1-32.

Bollerslev, T. "Generalised Autoregressive Conditional Heteroskedasticity." Journal of Econometrics 31(1986): 307-327.

Bollerslev, T. "Modelling the Coherence in Short-Run Nominal Exchange Rates: A Multivariate Generalised ARCH Model." Review of Economics and Statistics 72 (1990): 498-505.

Bollerslev, T., and J. Wooldridge (1992), 'Quasi-Maximum Likelihood Estimation and Inference in Dynamic Models with Time-Varying Covariances’, Econometric Reviews, 11, 143-172.

Bollerslev, T., R. Engle, and J. Wooldridge (1988), 'A Capital Asset Pricing Model With Time-Varying Covariance', Journal of Political Economy, 96, 116-131.

Diebold, F., and Nerlove, M. (1989), 'The Dynamics of Exchange Rate Volatility: a Multivariate Latent Factor Arch Model', Journal of Applied Econometrics, 4, 1-21.

Ding, Z., R. Engle, and C. Granger (1993), 'A Long-memory Property of Stock Market Returns and a New Model', Journal of Empirical Finance, 1, 107-131.

Engle, R.F. "Discussion: Stock Market Volatility and the Crash of 87." Review of Financial Studies 3 (1990): 103-6.

Engle, R. (2002), 'Dynamic Conditional Correlation: A Simple Class of Multivariate Generalized Autoregressive Conditional Heteroskedasticity Models', Journal of Business and Economic Statistics, 20, 339-350.

Engle, R., and Kroner, K. (1995), 'Multivariate Simultaneous Generalized ARCH', Econometric Theory, 11, 122-150.

Gao, S. (2002), "China Stock Market in a Global Perspective," http://www.djindexes.com/mdsidx/downloads/china_mkt_WP.pdf

Sentana, E. (1995), 'Quadratic ARCH Models', Review of Economic Studies, 62, 639-661.

Tse, Y., and A. Tsui (2002), 'A Multivariate Generalized Autoregressive Conditional Heteroskedasticity Model with Time-varying Correlations', Journal of Business and Economic Statistics, 20, 351-362. 